\title{
Association of the KDIGO Risk Classification with the Prevalence of Heart Failure in Patients with Type 2 Diabetes
}

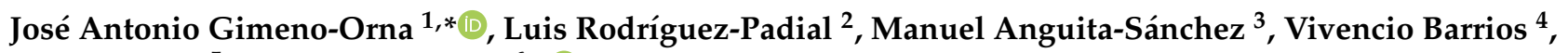 \\ Javier Muñiz ${ }^{5}$ and Antonio Pérez ${ }^{6, *}$
}

check for

updates

Citation: Gimeno-Orna, J.A.;

Rodríguez-Padial, L.;

Anguita-Sánchez, M.; Barrios, V.;

Muñiz, J.; Pérez, A. Association of the

KDIGO Risk Classification with the

Prevalence of Heart Failure in

Patients with Type 2 Diabetes. J. Clin. Med. 2021, 10, 4634. https://doi.org/ $10.3390 /$ jcm10204634

\section{Academic Editors: Jose}

Luis Sanchez-Quesada and

Andrzej Surdacki

Received: 4 August 2021

Accepted: 2 October 2021

Published: 9 October 2021

Publisher's Note: MDPI stays neutral with regard to jurisdictional claims in published maps and institutional affiliations.

Copyright: (C) 2021 by the authors. Licensee MDPI, Basel, Switzerland. This article is an open access article distributed under the terms and conditions of the Creative Commons Attribution (CC BY) license (https:// creativecommons.org/licenses/by/ $4.0 /)$.
1 Endocrinology and Nutrition Service, Hospital Clínico Universitario Lozano Blesa, 50009 Zaragoza, Spain

2 Cardiology Service, Complejo Hospitalario de Toledo, 45004 Toledo, Spain; lrpadial@gmail.com

3 Cardiology Service, Hospital Universitario Reina Sofía, Instituto Maimónides de Investigación Biomédica (IMIBIC), Universidad de Córdoba, 14004 Córdoba, Spain; manuelanguita@secardiologia.es

4 Cardiology Service, Hospital Universitario Ramón y Cajal, 28034 Madrid, Spain; vivenciobarrios@gmail.com

5 Coruña University, Cardiovascular Research Group, Health Sciences Department and Biomedic Research Institute de A Coruña (INIBIC), CIBERCV, 15006 A Coruña, Spain; javmu@odds.es

6 Endocrinology and Nutrition Service and Research Institute (IIB Sant Pau) of the Hospital de la Santa Creu i Sant Pau, Universidad Autónoma de Barcelona, CIBER de Diabetes y Enfermedades

Metabólicas (CIBERDEM), 08023 Barcelona, Spain

* Correspondence: jagimeno@salud.aragon.es (J.A.G.-O.); aperez@santpau.cat (A.P.); Tel.: +34-692-20-82-57 (J.A.G.-O.); +34-355-35-657 (A.P.)

Abstract: The objectives of this study were to determine the main characteristics associated with the presence of heart failure (HF) in patients with type 2 diabetes (T2DM), and specifically to assess the association of the risk classification proposed by the Kidney Disease Improving Global Outcomes (KDIGO) guidelines with HF. The DIABET-IC study is a multicentre, observational, prospective and analytical study in T2DM patients recruited in Spanish hospitals. This work, which features a cross-sectional design, has been conducted with the data obtained at the inclusion visit. The main dependent variable analysed was the presence of HF. The predictive variables evaluated were the demography, clinic, laboratory testing (including natriuretic peptides) and echocardiography. Patients were classified according to the number of vascular territories with atherosclerotic involvement and the KDIGO risk category. Multivariate logistic regression models were performed to determine the risk posed by the various baseline variables to present $\mathrm{HF}$ at the time of study inclusion. The study included 1517 patients from 58 hospitals, with a mean age of 67.3 (standard deviation (SD): 10) years, out of which 33\% were women. The mean DM duration was 14 (SD: 11) years. The prevalence of HF was 37\%. In a multivariate analysis, the independent predictors of HF were increased age (odds ratio $(\mathrm{OR})$ per 1 year $=1.02 ; p=0.006$ ), decreased systolic blood pressure (OR per $1 \mathrm{mmHg}=0.98 ; p<0.001)$, decreased haemoglobin (OR per $1 \mathrm{~g} / \mathrm{dL}=0.86$; $p<0.001)$, the presence of obstructive sleep apnoea ( $\mathrm{OR}=1.61 ; p=0.006)$, the absence of hepatic steatosis $(\mathrm{OR}=0.59 ; p=0.016)$, the severity of atherosclerotic involvement (OR 1 territory $=1.38$ and $\mathrm{OR}>1$ territory $=2.39 ; p=0.02$ and $p<0.001$ respectively) and the KDIGO risk classification (high-risk $\mathrm{OR}=2.46$ and very high-risk $\mathrm{OR}=3.39 ; p<0.001$ for both). The KDIGO risk classification is useful to screen for the presence of HF in T2DM patients. Therefore, we believe that it is necessary to carry out a systematic screening for HF in the high- and very high-risk KDIGO categories.

Keywords: type 2 diabetes; cardiovascular disease; heart failure; KDIGO risk category

\section{Introduction}

It is widely known that patients with diabetes have an increased risk of cardiovascular disease (CVD) [1]. The presence of diabetes mellitus increases the risk of heart failure (HF) by more than $50 \%$. At present, HF is the second most frequent manifestation of CVD in patients with type 2 diabetes mellitus (T2DM) [2]. In a large population-based study, the 
most important risk factors identified for HF hospitalization in T2DM patients were atrial fibrillation, excess body weight and the loss of renal function [3]. In fact, despite having $\mathrm{HbA1c}$ levels, blood pressure, LDL-cholesterol and urinary albumin excretion within the recommended targets, the increased risk given by T2DM is not completely neutralised.

Pathophysiologically, the increased risk of HF in T2DM patients can be attributed to the presence of ischemic heart disease (myocardial infarction being a main cause of HF with reduced ejection fraction), high blood pressure and the presence of a specific diabetic cardiomyopathy [4]. Insulin resistance, hyperglycaemia, myocardial lipotoxicity with mitochondrial dysfunction and oxidative stress, and the inflammatory response lead to myocardial fibrosis and diastolic dysfunction [5]. Myocardial microvascular dysfunction is considered to play a key role in the development of HF with preserved ejection fraction [6].

The development of diabetic chronic kidney disease (CKD) is an additional factor that increases the likelihood of HF, mainly because it facilitates the development of atherosclerotic lesions, fibrosis, left ventricular hypertrophy and valvular calcifications [7]. The 2012 Guidelines of the Kidney Disease Improving Global Outcomes (KDIGO) [8] define four risk categories for the combined prognosis of total mortality, cardiovascular mortality and events related to the flare-up and progression of CKD, but do not specifically mention its importance as a predictive factor of HF.

Treatment with SGLT2 inhibitors has been associated with reduced risk of HF. Currently, all guidelines recommend the use of SGLT2 inhibitors in the presence of HF, especially with reduced ejection fraction $[9,10]$. Since HF in T2DM patients is a frequent and clinically relevant condition that can be improved with specific treatments, its early detection is essential [11].

Recent international guidelines acknowledge the relevance of HF in DM patients and recommend atrial fibrillation screening [12]. However, beyond the clinical suspicion and classical risk factors monitoring [13], they do not establish specific recommendations on the need to determine natriuretic peptides or perform an echocardiogram.

Our hypothesis was that the probability of a T2DM patient having HF could be predicted from the existence or absence of easily identifiable clinical risk conditions. After natriuretic peptide-based screening, the performance of specific tests (echocardiogram) could confirm the diagnosis and lead to an appropriate treatment.

Our objective, based on the baseline data from the DIABET-IC study (Spanish multicentre study on the prevalence and incidence of heart failure in patients with type 2 diabetes in hospital consultation rooms throughout the country), was to determine the main characteristics associated with the risk of presenting HF, with a special focus on evaluating the usefulness of the risk classification proposed by the KDIGO guidelines.

\section{Material and Methods}

\subsection{Design}

The DIABET-IC study is a multicentre, observational, prospective and analytical study conducted in Spanish hospitals promoted by the Spanish Society of Diabetes (SED) and the Spanish Society of Cardiology (SEC). It has an observational, pragmatic design, with a follow-up of patients under conditions of routine clinical practice. After the initial visit, the planned follow-up was 3 years. The study was conducted in accordance with the Declaration of Helsinki, and it was approved by the Ethics Committee of Toledo Hospital Complex on 28 March 2018 (project identification code 243). All patients signed an informed consent to participate.

This work, with a cross-sectional design, has been conducted with the data obtained from patients in the inclusion visit between 2018 and 2019.

\subsection{Patients}

The inclusion criteria were patients aged 18 years or older, with type 2 diabetes diagnosed at least 1 year before the study start according to the Criteria of the American Diabetes Association (ADA) in force at that time [14]. Patients with type 1 diabetes, with 
the presence of stage 5 chronic kidney disease or with an estimated life expectancy of less than 3 years due to neoplasms or other serious systemic diseases were excluded.

The subjects were to be seen in external endocrinology and/or cardiology consultation rooms. Each participating centre could include a maximum of 40 patients (20 from endocrinology and 20 from cardiology units). Recruitment was consecutive to avoid selection bias.

The expected sample size was 2400 patients distributed in 60 centres. This sample size, with a confidence level of $95 \%$, would allow the estimation of the incidence of HF for 3 years with an absolute accuracy of $0.6 \%$. However, due to recruitment problems, the desired number of patients was not reached.

\subsection{Primary Dependent Variable}

The main dependent variable analysed was the presence of HF at the inclusion visit. The definition of HF was collected in the guidelines of the European Society of Cardiology (ESC) [15] in 2016. HF was classified as HF with reduced ejection fraction (HFrEF) if the left ventricular ejection fraction (EF) was less than $40 \%$. Due to the limited number of patients, all those with EF greater than or equal to $40 \%$ were considered subjects with preserved EF (HFpEF). In a sensitivity analysis, an EF cut-off point of $50 \%$ was selected for the definition of HFpEF.

\subsection{Variables Obtained at Inclusion}

Demographic data (age, sex), lifestyle (smoking status, alcohol consumption) and concomitant pathologies: coronary artery disease (CAD), defined as a history of acute myocardial infarction, revascularization or coronary stenosis $>50 \%$; cerebrovascular disease (CD), defined as a history of stroke or carotid stenosis $>50 \%$; peripheral artery disease (PAD), defined as lower limb artery disease; atherosclerotic cardiovascular disease (ACVD), defined as CAD and/or CD and/or PAD, with classification of the number of affected territories into 3 categories (none, one, or more than one); chronic obstructive pulmonary disease (COPD); obstructive sleep apnoea syndrome (OSA); high blood pressure (HBP), defined as blood pressure $>140 / 90 \mathrm{mmHg}$ or taking hypotensive drugs; atrial fibrillation (AF); fatty liver disease (FLD); and finally the Charlson score.

Data related to T2DM: disease duration; result of the ocular fundus examination, classifying the findings as normal, simple retinopathy or proliferative retinopathy; presence of neuropathy by clinical diagnosis; presence of nephropathy, defined as glomerular filtration rate (GFR) $<60 \mathrm{~mL} / \mathrm{min} / 1.73 \mathrm{~m}^{2}$ and/or urinary albumin excretion rate (UAER) $\geq 30 \mathrm{mg} / \mathrm{g}$.

Physical examination: weight and height measurements in light clothing and without footwear, with estimation of body mass index (BMI) in the form of weight $(\mathrm{Kg}) /$ height $(\mathrm{m})^{2}$; measurement of systolic and diastolic blood pressure, with the patient seated, after at least $5 \mathrm{~min}$ of rest, and with a cuff appropriate to the circumference of the arm.

Fasting blood sample collection to measure: glycaemia (mg/dL); HbA1c (\%); lipid profile (total cholesterol, triglycerides, HDL-cholesterol), with non-HDL cholesterol (NHDLC) calculation (total cholesterol-HDL) expressed in $\mathrm{mg} / \mathrm{dL}$; creatinine $(\mathrm{mg} / \mathrm{dL}$ ), with determination of GFR using the CKD-EPI formula; UAER in a morning urine sample, expressed in $\mathrm{mg} / \mathrm{g}$ of creatinine; haemoglobin ( $\mathrm{g} / \mathrm{dL}$ ); natriuretic peptides (BNP or NT-proBNP) expressed in $\mathrm{pg} / \mathrm{mL}$. Measurements were made in each participating hospital following routine procedures.

Electrocardiogram, with rhythm assessment.

Echocardiogram, with measurement of left ventricular ejection fraction (LVEF). The procedure was conducted in each of the participating centres, and patients were classified in 3 categories: preserved $(\geq 50 \%)$, intermediate $(40-49 \%)$ and reduced $(<40 \%)$, with subsequent recoding into 2 categories: preserved $(\geq 40 \%)$ or reduced $(<40 \%)$. 
Patients were also classified based on their GFR (expressed in $\mathrm{mL} / \mathrm{min} / 1.73 \mathrm{~m}^{2}$ ) and UAER (expressed in $\mathrm{mg} / \mathrm{g}$ of creatinine) in 4 risk categories, following the indications of the KDIGO guideline [8]:

Low risk: GFR $\geq 60$ and $U A E R<30$.

Moderate risk: GFR $\geq 60$ and UAER 30-300 or GFR 45-59 and UAER $<30$.

High risk: GFR $\geq 60$ and UAER $>300$ or GFR 45-59 and UAER 30-300 or GFR 30-44 and UAER $<30$.

Very high risk: GFR 45-59 and UAER > 300 or GFR 30-44 and UAER $\geq 30$ or GFR $<30$.

\subsection{Statistical Methods}

The quantitative variables were described with their mean and standard deviation (SD) or as median with interquartile range. Qualitative variables were expressed as frequency distribution in \%.

A comparison of quantitative variables was made with the student's $t$ test on independent samples or ANOVA, or with non-parametric tests if the assumptions of normality were violated. The comparison of qualitative variables was done with $\mathrm{X}^{2}$ test.

Logistic regression models were performed to determine the risk conferred by the different variables to show $\mathrm{HF}$ at the time of study inclusion, calculating the odds ratio (OR) with its $95 \%$ confidence interval (CI). Univariate and multivariate analyses were performed. The criteria for the inclusion of the variables in the models were based on their significance in the univariate analysis $(p<0.05)$ or on their clinical meaning. Highly correlated variables were not included simultaneously.

The initial multivariate model included age, sex, COPD, smoking status, HBP (or alternatively systolic and diastolic blood pressure), NHDLC, BMI, OSA, FLD, T2DM duration, presence of retinopathy, $\mathrm{HbA1c}$, haemoglobin, KDIGO risk classification, (or alternatively GFR and UAER), AF, CAD, CD and PAD (or alternatively the number of vascular territories affected). The values of natriuretic peptide tests were not included because they were involved in the diagnostic process. Finally, a sequential exclusion procedure was performed to obtain the independent risk factors of presenting HF.

In a sensitivity analysis, we included in the multivariate models a variable named "origin of the patients."

Associations with a $p<0.05$ were considered significant.

\section{Results}

A total of 1517 patients from 58 Spanish hospitals were included, with a mean age of 67.3 (SD 10) years, of which 33\% were women. The mean T2DM duration was 14 (SD 11) years, with $42.6 \%$ of patients receiving insulin treatment. The proportion of patients with chronic complications was: $12.5 \%$ retinopathy (7.6\% simple and $4.9 \%$ proliferative), $30.3 \%$ nephropathy, 5.6\% neuropathy and 49\% ACVD (38.2\% with an affected territory and 10.8\% with more than one affected territory). Regarding the KDIGO risk categories, $56.3 \%$ of the patients were low risk, $23.3 \%$ moderate, $12 \%$ high and $8.4 \%$ very high.

The proportion of patients with protective cardiovascular treatments was high: 40.5\% on SGLT2 inhibitors, $16.5 \%$ on GLP1 receptor agonists, $68.6 \%$ on ACEI or ARB, $58.5 \%$ on beta-blockers, $21.2 \%$ on mineralocorticoid receptor antagonists, $11 \%$ on sacubitril-valsartan, $84 \%$ on statins, $0.9 \%$ on PCSK9 inhibitors, $52.7 \%$ on antiplatelet agents and $25.7 \%$ on oral anticoagulants.

Valid data were obtained for the HF classification in 1497 patients. The prevalence of HF was 37\% (16\% EF < 40\%; 8\% EF 40-49\%; 13\% EF $\geq 50 \%)$. The prevalence of HF increased statistically significantly in patients with OSA, in patients with AF, in the presence of ACVD (especially in patients with PAD and as the number of affected territories increased) and in the successive risk categories according to the KDIGO classification (Figure 1). The prevalence was higher than $50 \%$ in subjects with AF $(66.7 \%)$, in the KDIGO very high-risk category $(66 \%)$, with an atherosclerotic involvement of more than 1 vascular territory 
(56.7\%) and with the presence of PAD (52.4\%). The Supplementary Figure S1 shows the prevalence of $\mathrm{HF}$ with $\mathrm{EF}<40 \%$ and $\geq 40 \%$ separately.

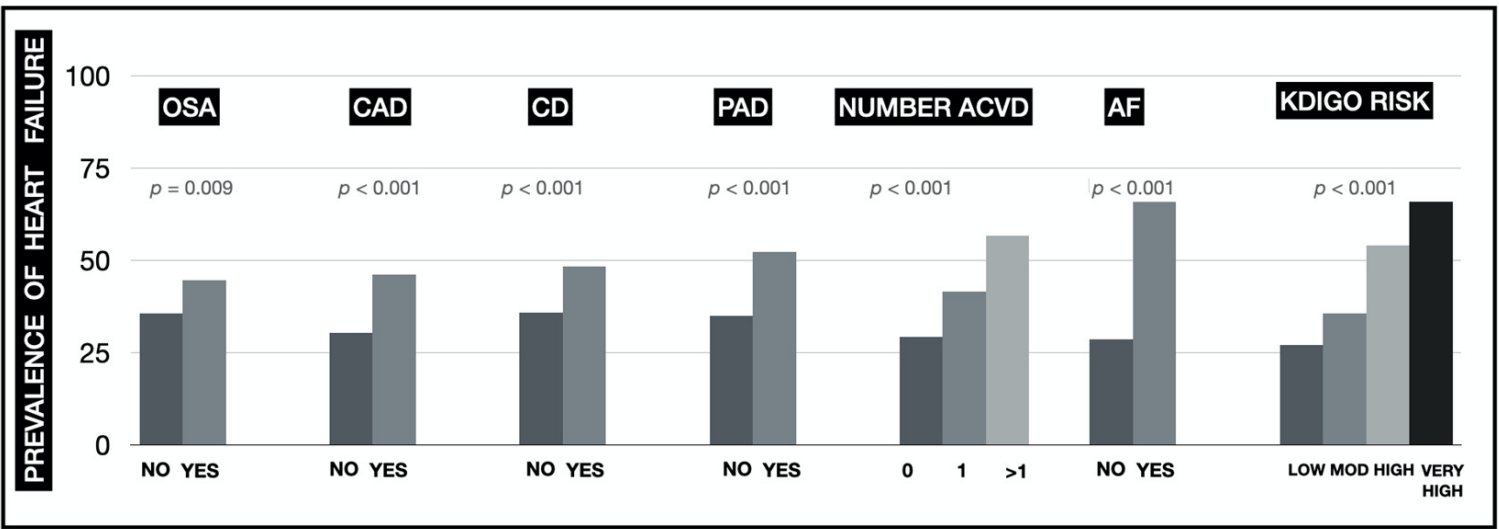

Figure 1. Prevalence of HF based on the patients' concomitant conditions (OSA: obstructive sleep apnoea syndrome; CAD: coronary artery disease; CD: cerebrovascular disease; PAD: peripheral artery disease; ACVD: atherosclerotic cardiovascular disease; AF: atrial fibrillation; KDIGO: Kidney Disease Improving Global Outcomes).

As expected, the prevalence of HF was higher in patients coming from the cardiology units than in those coming from the endocrinology units $(51.6 \%$ vs $16 \% ; p<0.001)$. The distribution of patients with $\mathrm{EF}<40 \%$ and $\geq 40 \%$ was different between both units: $25.1 \%$ and $26.5 \%$, respectively, in cardiology vs $2.9 \%$ and $13.1 \%$, respectively, in endocrinology $(p<0.001)$. There was also a higher proportion of patients with ACVD $(61.2 \%$ vs $31.7 \%$; $p<0.001)$ in the cardiology sample.

Table 1 compares the patients' characteristics based on whether they had HF at baseline. Patients with HF were older; had a higher prevalence of COPD, OSA, ACVD and AF; and a lower prevalence of FLD. They also had lower blood pressure and lower NHDLC, haemoglobin and GFR levels, but higher values of UAER and NT-proBNP. Interestingly, patients with HF were characterized by having a greater number of vascular territories affected by atherosclerosis, and a higher proportion of subjects were in the KDIGO highand very high-risk categories. Table 2 further compares the patients with HF depending on whether their EF is less than $40 \%$. The Supplementary Table S1 uses the alternative cut-off point of $50 \%$.

In the multivariate analyses, the independent predictors of the presence of HF (Table 3) were increased age (OR per 1 year 1.02; $p=0.006)$, decreased systolic blood pressure (OR per $1 \mathrm{mmHg}=0.98 ; p<0.001)$ and haemoglobin (OR per $1 \mathrm{~g} / \mathrm{dL}=0.86 ; p<0.001)$, the presence of OSA (OR $=1.61 ; p=0.006)$, KDIGO risk classification (high-risk OR $=2.46$ and very high-risk $\mathrm{OR}=3.39 ; p<0.001$ both $)$ and the presence of $\mathrm{ACVD}(\mathrm{OR} 1$ territory $=1.38$ and OR more than one territory $=2.39 ; p=0.02$ and $p<0.001$ respectively). Conversely, the presence of FLD was a protective factor in the limit of statistical significance ( $O R=0.59$; $p=0.016)$. The statistical significance of FLD was lost after adjusting for origin of the patients $(\mathrm{OR}=0.83 ; p=0.41)$. 
Table 1. Patients' baseline characteristics and univariate OR for the risk of having HF.

\begin{tabular}{|c|c|c|c|c|c|c|c|}
\hline \multicolumn{2}{|c|}{ Variable } & $\begin{array}{c}\text { Total Group } \\
n=1497\end{array}$ & $\begin{array}{c}\text { No Heart Failure } \\
n=943\end{array}$ & $\begin{array}{l}\text { Heart Failure } \\
\quad n=554\end{array}$ & $p$ & OR & $95 \%$ CI \\
\hline \multicolumn{2}{|c|}{ Age (years) } & $67.3(10.1)$ & $65.9(9.9)$ & $69.8(9,9)$ & $<0.001$ & 1.04 & $1.03-1.05$ \\
\hline \multicolumn{2}{|c|}{ Gender (\% female) } & $501(33)$ & $320(33.9)$ & $169(30.5)$ & 0.17 & 0.86 & $0.68-1.07$ \\
\hline \multicolumn{2}{|c|}{ Current smoking (\%) } & $164(10.8)$ & $116(12.3)$ & $46(8.3)$ & 0.12 & 0.74 & $0.51-1.08$ \\
\hline \multicolumn{2}{|c|}{ Hypertension (\%) } & $1244(81.9)$ & $763(80.9)$ & $466(84.1)$ & 0.12 & 1.25 & $0.94-1.65$ \\
\hline \multicolumn{2}{|c|}{$\begin{array}{c}\text { Chronic obstructive pulmonary } \\
\text { disease }(\%)\end{array}$} & $166(10.9)$ & $79(8.4)$ & $85(15.3)$ & $<0.001$ & 1.98 & $1.43-2.75$ \\
\hline \multicolumn{2}{|c|}{ Obstructive sleep apnoea (\%) } & $232(15.3)$ & $126(13.4)$ & $102(18.4)$ & 0.009 & 1.46 & $1.10-1.95$ \\
\hline \multicolumn{2}{|c|}{ Fatty liver disease $(\%)$} & $181(12.1)$ & $132(14.2)$ & $43(7.8)$ & $<0.001$ & 0.51 & $0.35-0.73$ \\
\hline \multicolumn{2}{|c|}{ Auricular fibrillation (\%) } & $327(21.6)$ & $108(11.4)$ & $217(39.2)$ & $<0.001$ & 4.98 & $3.83-6.48$ \\
\hline \multicolumn{2}{|c|}{ Coronary artery disease (\%) } & $633(41.9)$ & $339(36)$ & $291(52.5)$ & $<0.001$ & 1.97 & $1.59-2.44$ \\
\hline \multicolumn{2}{|c|}{ Cerebrovascular disease (\%) } & $128(8.5)$ & $66(7)$ & $62(11.2)$ & $<0.001$ & 1.67 & $1.16-2.41$ \\
\hline \multicolumn{2}{|c|}{ Peripheral artery disease (\%) } & $164(10.8)$ & $78(8.3)$ & $86(15.5)$ & $<0.001$ & 2.04 & $1.47-2.82$ \\
\hline \multicolumn{2}{|c|}{$\begin{array}{l}\text { Atherosclerotic cardiovascular } \\
\text { disease }(\%)\end{array}$} & $741(49)$ & $406(43)$ & $332(59.9)$ & $<0.001$ & 1.98 & $1.60-2.45$ \\
\hline \multirow{3}{*}{$\begin{array}{l}\text { Number of } \\
\text { vascular } \\
\text { territories } \\
\text { affected }\end{array}$} & $0(\%)$ & $771(51)$ & $537(57)$ & $222(40.1)$ & \multirow{3}{*}{$<0.001$} & 1 & - \\
\hline & $1(\%)$ & $577(38.2)$ & $335(35.5)$ & $239(43.1)$ & & 1.73 & $1.37-2.17$ \\
\hline & $>1(\%)$ & $164(10.8)$ & $71(7.5)$ & $93(16.8)$ & & 3.17 & $2.24-4.48$ \\
\hline \multicolumn{2}{|c|}{ Charlson index (points) } & $0.62(0.88)$ & $0.52(0.8)$ & $0,81(0.98)$ & $<0.001$ & 1.44 & $1.28-1.62$ \\
\hline \multirow[b]{2}{*}{ Retinopathy } & Simple (\%) & $114(7.6)$ & $77(8.2)$ & $32(5.8)$ & \multirow[b]{2}{*}{0.29} & 0.69 & $0.45-1.05$ \\
\hline & $\begin{array}{c}\text { Proliferative } \\
(\%)\end{array}$ & $74(4.9)$ & $45(4.8)$ & $29(5.2)$ & & 1.07 & $0.66-1.72$ \\
\hline \multicolumn{2}{|c|}{ Body mass index $\left(\mathrm{Kg} / \mathrm{m}^{2}\right)$} & $30.3(5.2)$ & $30.3(5.1)$ & $30.1(5.4)$ & 0.57 & 1.00 & $0.98-1.02$ \\
\hline \multicolumn{2}{|c|}{ Systolic blood pressure (mmHg) } & $135(19.4)$ & $138(18)$ & $129(21)$ & $<0.001$ & 0.98 & $0.97-0.98$ \\
\hline \multicolumn{2}{|c|}{ Diastolic blood pressure (mmHg) } & $76(11.5)$ & $77(11)$ & $73(11)$ & $<0.001$ & 0.96 & $0.95-0.97$ \\
\hline \multicolumn{2}{|c|}{ Diabetes duration (years) } & $14(11.1)$ & $13.7(9.9)$ & $14.7(12.9)$ & 0.14 & 1.01 & $1.00-1.02$ \\
\hline \multicolumn{2}{|c|}{$\mathrm{HbA1c}(\%)$} & $7.3(1.3)$ & $7.3(1.3)$ & $7.2(1.3)$ & 0.12 & 0.94 & $0.86-1.02$ \\
\hline \multicolumn{2}{|c|}{ Non-HDL cholesterol (mg/dL) } & $109(34.1)$ & $110(34)$ & $107(35)$ & 0.04 & 0.99 & $0.99-1.00$ \\
\hline \multicolumn{2}{|c|}{ Triglycerides $(\mathrm{mg} / \mathrm{dL}) *$} & $133(85)$ & $129(87)$ & $136(82)$ & 0.55 & 1.00 & $0.99-1.00$ \\
\hline \multicolumn{2}{|c|}{ Haemoglobin $(\mathrm{g} / \mathrm{dL})$} & $14(1.8)$ & $14.3(1.7)$ & $13.6(1.9)$ & $<0.001$ & 0.82 & $0.77-0.87$ \\
\hline \multicolumn{2}{|c|}{ NT-proBNP $(\mathrm{pg} / \mathrm{mL}) *$} & $243(782)$ & $127(245)$ & $851(1958)$ & $<0.001$ & 1.001 & $1.000-1.002$ \\
\hline \multicolumn{2}{|c|}{$\begin{array}{l}\text { Glomerular filtration rate } \\
\left(\mathrm{mL} / \mathrm{min} / 1.73 \mathrm{~m}^{2}\right)\end{array}$} & $73.1(22.7)$ & $77.9(20.8)$ & $64.6(23.5)$ & $<0.001$ & 0.97 & $0.96-0.98$ \\
\hline $\begin{array}{r}\text { Urinary alb } \\
(\mathrm{n}\end{array}$ & in excretion & $87(393)$ & $62(201)$ & $132(603)$ & 0.017 & 1.001 & $1.000-1.001$ \\
\hline & Low $(\%)$ & $715(56.4)$ & $518(63.6)$ & $194(43)$ & & 1 & - \\
\hline VDIC & Moderate (\%) & $295(23.3)$ & $190(23.4)$ & $105(23.3)$ & & 1.48 & $1.10-1.97$ \\
\hline NDIGU TISK & High $(\%)$ & $152(12)$ & $70(8.6)$ & $82(18.2)$ & $<0.001$ & 3.13 & $2.18-4.48$ \\
\hline & Very high (\%) & $106(8.4)$ & $36(4.4)$ & $70(15.5)$ & & 5.19 & $3.36-8.02$ \\
\hline
\end{tabular}

The values in the boxes are the number of patients (\%), mean (standard deviation) or median * (interquartile range). OR: odds ratio; CI: confidence interval; HbA1c: glycated haemoglobin; HDL: High-density lipoprotein; NT-proBNP: N-terminal fragment of brain natriuretic peptide; KDIGO: Kidney Disease Improving Global Outcomes. 
Table 2. Patients' baseline characteristics based on the type of HF.

\begin{tabular}{|c|c|c|c|c|c|c|c|}
\hline \multicolumn{2}{|c|}{ Variable } & $\begin{array}{c}\text { Total Group } \\
n=1497\end{array}$ & $\begin{array}{c}\text { Group 1: No } \\
\text { Heart Failure } \\
n=943\end{array}$ & $\begin{array}{c}\text { Group 2: HF } \\
\text { with EF < 40\% } \\
n=240\end{array}$ & $\begin{array}{c}\text { Group 3: HF } \\
\text { with } \mathrm{EF} \geq 40 \% \\
n=314\end{array}$ & $p$ & $p \underset{\text { vs } 3}{\operatorname{Group}} 2$ \\
\hline \multicolumn{2}{|c|}{ Age (years) } & $67.3(10.1)$ & $65.9(9.9)$ & $68.1(9.9)$ & $71.1(9.7)$ & $<0.001$ & $<0.001$ \\
\hline \multicolumn{2}{|c|}{ Gender ( $\%$ female) } & $501(33)$ & $320(33.9)$ & $52(21.7)$ & $117(37.2)$ & $<0.001$ & $<0.001$ \\
\hline \multicolumn{2}{|c|}{ Current smoking (\%) } & $164(10.8)$ & $116(12.3)$ & $27(11.2)$ & $19(6.1)$ & $<0.001$ & 0.017 \\
\hline \multicolumn{2}{|c|}{ Hypertension (\%) } & $1244(81.9)$ & $763(80.9)$ & $188(78.3)$ & $278(88.5)$ & 0.002 & 0.001 \\
\hline \multicolumn{2}{|c|}{$\begin{array}{l}\text { Chronic obstructive } \\
\text { pulmonary disease }(\%)\end{array}$} & $166(10.9)$ & $79(8.4)$ & $39(16.2)$ & $46(14.6)$ & $<0.001$ & 0.60 \\
\hline \multicolumn{2}{|c|}{ Obstructive sleep apnoea (\%) } & $232(15.3)$ & $126(13.4)$ & $37(15.4)$ & $65(20.7)$ & 0.007 & 0.11 \\
\hline \multicolumn{2}{|c|}{ Fatty liver disease (\%) } & $181(12.1)$ & $132(14.2)$ & $14(5.9)$ & $29(9.3)$ & $<0.001$ & 0.14 \\
\hline \multicolumn{2}{|c|}{ Auricular fibrillation (\%) } & $327(21.6)$ & $108(11.4)$ & $92(38.3)$ & $125(39.8)$ & $<0.001$ & 0.72 \\
\hline \multicolumn{2}{|c|}{ Coronary artery disease (\%) } & $633(41.9)$ & $339(36)$ & $148(61.6)$ & $143(45.5)$ & $<0.001$ & $<0.001$ \\
\hline \multicolumn{2}{|c|}{ Cerebrovascular disease (\%) } & $128(8.5)$ & $66(7)$ & $28(11.7)$ & $34(10.8)$ & 0.019 & 0.76 \\
\hline \multicolumn{2}{|c|}{ Peripheral artery disease (\%) } & $164(10.8)$ & $78(8.3)$ & $37(15.4)$ & $49(15.6)$ & $<0.001$ & 0.95 \\
\hline \multicolumn{2}{|c|}{$\begin{array}{c}\text { Atherosclerotic cardiovascular } \\
\text { disease }(\%)\end{array}$} & $741(49)$ & $406(43)$ & $164(68.3)$ & $168(53.5)$ & $<0.001$ & $<0.001$ \\
\hline \multirow{3}{*}{$\begin{array}{l}\text { Number of } \\
\text { vascular } \\
\text { territories } \\
\text { affected }\end{array}$} & 0 & $771(51)$ & $537(57)$ & $76(31.7)$ & $146(46.5)$ & \multirow{3}{*}{$<0.001$} & \multirow{3}{*}{0.002} \\
\hline & 1 & $577(38.2)$ & $335(35.5)$ & $120(50)$ & $119(37.9)$ & & \\
\hline & $>1$ & $164(10.8)$ & $71(7.5)$ & $44(18.3)$ & $49(15.6)$ & & \\
\hline \multicolumn{2}{|c|}{ Charlson index (points) } & $0.62(0.88)$ & $0.52(0.8)$ & $0.78(0.95)$ & $0.83(1.00)$ & $<0.001$ & 0.50 \\
\hline \multirow[b]{2}{*}{ Retinopathy } & Simple (\%) & $114(7.6)$ & $77(8.2)$ & $14(5.8)$ & $18(5.7)$ & \multirow[b]{2}{*}{0.64} & \multirow[b]{2}{*}{0.88} \\
\hline & $\begin{array}{c}\text { Proliferative } \\
(\%)\end{array}$ & $74(4.9)$ & $45(4.8)$ & $13(5.4)$ & $16(5.1)$ & & \\
\hline \multicolumn{2}{|c|}{ Body mass index $\left(\mathrm{Kg} / \mathrm{m}^{2}\right)$} & $30.3(5.2)$ & $30.3(5.1)$ & $29.4(5.3)$ & $30.7(5.4)$ & 0.012 & 0.005 \\
\hline \multicolumn{2}{|c|}{$\begin{array}{l}\text { Systolic blood pressure } \\
(\mathrm{mmHg})\end{array}$} & $135(19.4)$ & $138(18)$ & $126(19.8)$ & $132(19.8)$ & $<0.001$ & $<0.001$ \\
\hline \multicolumn{2}{|c|}{$\begin{array}{l}\text { Diastolic blood pressure } \\
(\mathrm{mmHg})\end{array}$} & $76(11.5)$ & $77(11)$ & $72(11.8)$ & $73(11.2)$ & $<0.001$ & 0.10 \\
\hline \multicolumn{2}{|c|}{ Diabetes duration (years) } & $14(11.1)$ & $13.7(9.9)$ & $15.4(15.3)$ & $14.1(10.7)$ & 0.1 & 0.46 \\
\hline \multicolumn{2}{|c|}{$\mathrm{HbA} 1 \mathrm{c}(\%)$} & $7.3(1.3)$ & $7.3(1.3)$ & $7.2(1.2)$ & $7.3(1.3)$ & 0.26 & 0.58 \\
\hline \multicolumn{2}{|c|}{$\begin{array}{l}\text { Non-HDL cholesterol } \\
\text { (mg/dL) }\end{array}$} & $109(34.1)$ & $110(34)$ & $104(34)$ & $109(35)$ & 0.026 & 0.09 \\
\hline \multicolumn{2}{|c|}{ Triglycerides $(\mathrm{mg} / \mathrm{dL})^{*}$} & $133(85)$ & $129(87)$ & $134(82)$ & $138(84)$ & 0.33 & 0.16 \\
\hline \multicolumn{2}{|c|}{ Haemoglobin (g/dL) } & $14(1.8)$ & $14.3(1.7)$ & $13.9(1.9)$ & $13.4(1.8)$ & $<0.001$ & 0.004 \\
\hline NT-proBN & $(\mathrm{pg} / \mathrm{mL})^{*}$ & $243(782)$ & $127(245)$ & 1089(2661) & $627(1563)$ & $<0.001$ & 0.038 \\
\hline Ejection $\mathrm{F}$ & action $(\%)$ & $54.9(13.4)$ & $61.5(7.6)$ & $32.8(7.9)$ & $54(10.4)$ & $<0.001$ & $<0.001$ \\
\hline $\begin{array}{r}\text { Glomerular } \\
(\mathrm{mL} / \mathrm{mir}\end{array}$ & $\begin{array}{l}\text { iltration rate } \\
\left(1.73 \mathrm{~m}^{2}\right)\end{array}$ & $73.1(22.7)$ & $77.9(20.8)$ & $66.3(23.1)$ & $66.3(23.8)$ & $<0.001$ & 0.14 \\
\hline $\begin{array}{r}\text { Urinary albu } \\
(\mathrm{m}\end{array}$ & $\begin{array}{l}\text { nin excretion } \\
/ g)\end{array}$ & 87 (393) & $62(201)$ & $165(825)$ & $112(404)$ & 0.004 & 0.36 \\
\hline & Low $(\%)$ & 715 (56.4) & $518(63.6)$ & $73(41.7)$ & $121(43.8)$ & & \\
\hline KDICO risk & Moderate (\%) & $295(23.3)$ & $190(23.4)$ & $42(24)$ & $63(22.8)$ & $<0001$ & 097 \\
\hline RDIGU IISK & High (\%) & $152(12)$ & $70(8.6)$ & $33(18.9)$ & 49 (17.7) & $<0.001$ & 0.97 \\
\hline & Very high (\%) & $106(8.4)$ & $36(4.4)$ & $27(15.4)$ & 43 (15.6) & & \\
\hline
\end{tabular}

The values in the boxes are the number of patients (\%), mean (standard deviation) or median * (interquartile range). 
Table 3. Independent variables (multivariate analysis) associated with the risk of HF at the inclusion visit.

\begin{tabular}{|c|c|c|c|c|}
\hline \multicolumn{2}{|c|}{ Variable } & OR & $95 \%$ CI & $p$ \\
\hline \multicolumn{2}{|c|}{ Age (years) } & 1.02 & $1.01-1.03$ & 0.006 \\
\hline \multicolumn{2}{|c|}{ Obstructive sleep apnoea } & 1.61 & $1.14-2.25$ & 0.006 \\
\hline \multicolumn{2}{|c|}{ Fatty liver disease } & 0.59 & $0.39-0.91$ & 0.016 \\
\hline \multicolumn{2}{|c|}{ Coronary artery disease } & 1.66 & $1.31-2.11$ & $<0.001$ \\
\hline \multicolumn{2}{|c|}{ Peripheral artery disease } & 1.53 & $1.06-2.23$ & 0.025 \\
\hline \multirow{3}{*}{$\begin{array}{l}\text { Number of vascular } \\
\text { territories affected }\end{array}$} & 0 & 1 & & - \\
\hline & 1 & 1.38 & $1.05-1.81$ & 0.02 \\
\hline & $>1$ & 2.39 & $1.59-3.60$ & $<0.001$ \\
\hline \multicolumn{2}{|c|}{ Systolic blood pressure (mmHg) } & 0.98 & $0.97-0.99$ & $<0.001$ \\
\hline \multicolumn{2}{|c|}{ Haemoglobin (g/dL) } & 0.86 & $0.80-0.93$ & $<0.001$ \\
\hline \multicolumn{2}{|c|}{ Glomerular filtration rate $\left(\mathrm{mL} / \mathrm{min} / 1.73 \mathrm{~m}^{2}\right)$} & 0.976 & $0.97-0.98$ & $<0.001$ \\
\hline \multirow{4}{*}{ KDIGO risk } & Low & 1 & & - \\
\hline & Moderate & 1.26 & $0.93-1.72$ & 0.14 \\
\hline & High & 2.46 & $1.67-3.64$ & $<0.001$ \\
\hline & Very high & 3.39 & $2.09-5.48$ & $<0.001$ \\
\hline
\end{tabular}

Figure 2 shows the distribution of patients and the adjusted OR for the prevalence of $\mathrm{HF}$ in the four KDIGO risk categories.

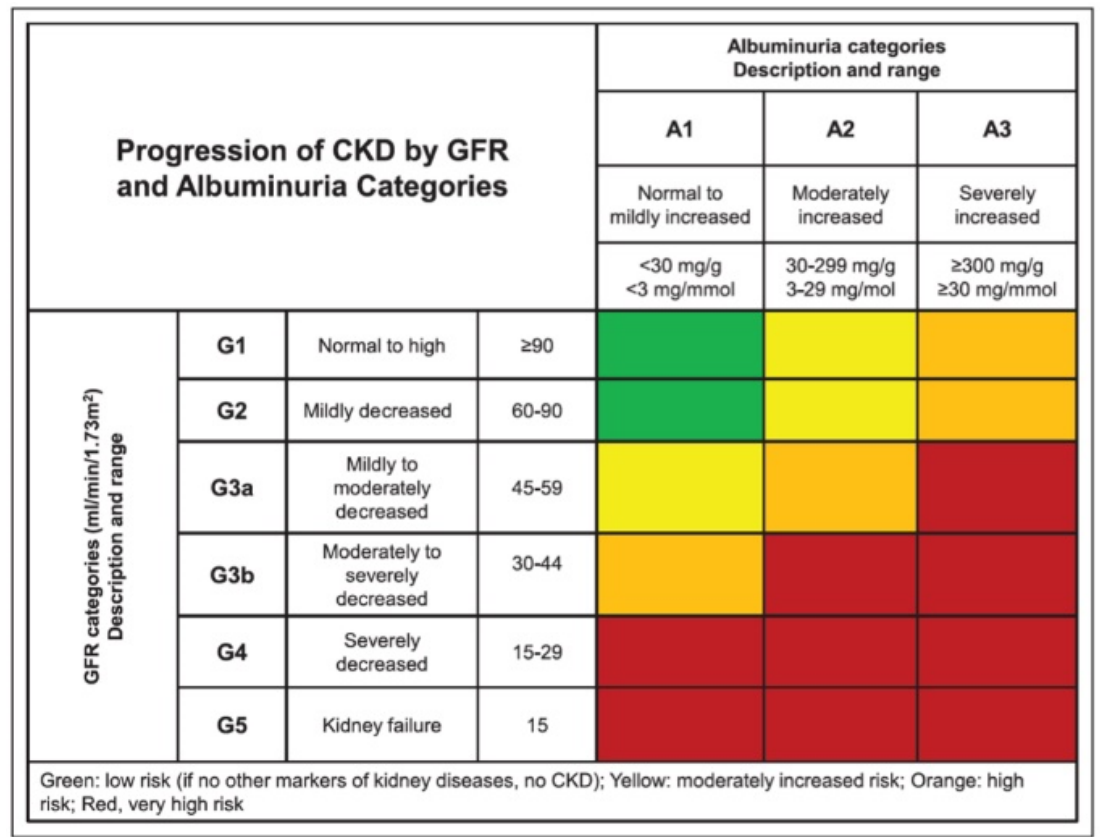

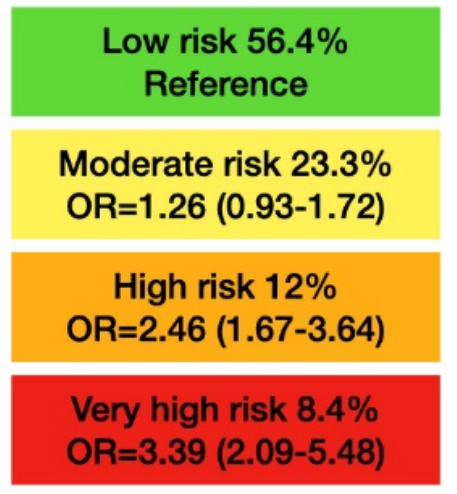

Figure 2. Distribution of the sample into the KDIGO categories and adjusted OR for the risk of having HF at the inclusion visit. CKD: chronic kidney disease; GFR: glomerular filtration rate; G: glomerular filtration rate categories; A: albuminuria categories; OR: odds ratio.

\section{Discussion}

In our work, conducted in a patient sample with T2DM coming from outpatient cardiology and endocrinology units, with a prevalence of HF of $37 \%$, we found that the 
main clinical conditions independently associated with the presence of HF were age, the presence of OSA, atherosclerotic CVD and renal involvement.

The prevalence of HF has increased in recent years, justified by the aging of the population and better survival after diagnosis [16]. T2DM and HF often coexist, and each disease increases the risk of the onset of the other [17]. In a meta-analysis of 31 studies with more than 41,000 patients, the prevalence of T2DM in patients with HF was $23 \%$, similar to the prevalence in patients with preserved or reduced EF [18].

Similarly, in a meta-analysis of cardiovascular safety trials in patients with T2DM, the prevalence of HF has been detected to be between $9 \%$ and $28 \%$, although without systematic performance of natriuretic peptide tests or echocardiogram [19]. The prevalence obtained in our study, 37\%, should be interpreted considering the origin of the patients and the performance of systematic screening. Although the sample derived from the cardiology units would be clearly biased toward obtaining high values, the prevalence of $16 \%$ obtained in patients recruited in the endocrinology units may be valid for subjects in the sixth decade of life and with a duration of the disease greater than 10 years. The higher proportion of HFrEF in cardiology patients can be justified by their greater presence of ACVD.

On the other hand, the number of comorbidities associated with the presence of HF has been described as high [16], ranging from 3.4 in 2002 to 5.4 in 2014. In our study, patients with HF, in addition to T2DM, had a higher prevalence of HBP (although with lower systolic blood pressure, especially in the case of $\mathrm{HFrEF}$, justified by the greater intensity of pharmacological treatment and/or deterioration of ventricular function), COPD, OSA, AF, atherosclerotic vascular involvement in any vascular territory and renal impairment.

Patients with OSA are characterized by higher blood pressure, insulin resistance and activity of the sympathetic nervous system, which favours the appearance of arrhythmias and HF [20]. In addition, they also have a higher prevalence of visceral obesity, which has harmful effects on the myocardium, favouring inflammation, fibrosis and the development of two strongly related pathologies, AF and HFpEF [21]. In our study, the presence of OSA increased the prevalence of HF by approximately $50 \%$ and the presence of AF increased risk by almost a factor of 5 , although this association was not statistically significant in the multivariate analysis.

PAD is the manifestation of ACVD most strongly associated with DM, and its presence may increase the risk of major cardiovascular events (MACE) even more than CAD [22] itself. In the DECLARE [23] study, patients with PAD had a higher prevalence of HF and a higher incidence of hospitalization for HF. More importantly, in both the FOURIER [24] and EMPA-REG OUTCOME [25] studies, the atherosclerotic involvement of multiple vascular territories has been shown to increase the risk of MACE and HF more than that of a single one. In our work, we found that the involvement of more than 1 vascular territory doubled the prevalence of HF.

The last aspect, and probably the most important, was that we found a great impact of the KDIGO risk classification (high- and very high-risk levels) on the prevalence of HF. This finding is biologically plausible [7], and has been supported by the observation that, in cardiovascular safety studies in type 2 diabetes enriched with patients with CKD, the incidence of HF hospitalization exceeds that of ACVD [19]. In a secondary analysis of the CANVAS [26] study, there was also an increase in the prevalence of HF and in the incidence rate of hospitalization for HF in the successive KDIGO risk categories, with the beneficial effect of canagliflozin being more marked in absolute terms in the highest risk categories. Given the association between HF and CKD, the KDIGO guidelines recommend developing strategies to diagnose and treat both conditions at an early stage [27]. Importantly, the additive effect of polyvascular disease and CKD found in our study on HF risk has also been confirmed in other populations [25]. Our additional finding that haemoglobin was a protective factor can be justified by its close relationship with renal function.

It was surprising to find a lower prevalence of FLD in patients with HF, since the association between hepatic fibrosis and diastolic dysfunction has been described [28]. However, in our sample, no imaging tests or biomarker panels were systematically per- 
formed, so the collected prevalence of FLD (12.1\%) was much lower than that described [29] in patients with T2DM, up to $70 \%$. Furthermore, the statistical significance of FLD was lost after adjusting for the origin of the patients.

As the strengths of our work, we highlight the recruitment of a large sample of T2DM patients, the systematic performance of natriuretic peptide tests and echocardiograms to accurately diagnose the prevalence of $\mathrm{HF}$, and the collection of multiple demographics, clinical and analytical variables to evaluate factors associated with the presence of HF. As for the weaknesses, it should be noted that the origin of the patients implies a selection bias, that the desired sample size was not reached due to recruitment problems, that the cross-sectional design did not allow the establishment of the causal effect of the associations found and that the multicentre design did not allow the standardization of biochemical and echocardiographic measurements. In fact, the associations of FLD and lower blood pressures with HF may be related to which clinic the diabetes patients came from and not potential etiologic associations.

In conclusion, we found that the KDIGO risk classification (high- and very high-risk categories), the presence of OSA and the existence of ACVD (especially in the case of polyvascular disease) are useful to predict the presence of HF in T2DM patients. Therefore, we consider it necessary to perform a systematic screening of HF in T2DM patients who meet these criteria to administer the appropriate treatment and improve the prognosis.

Supplementary Materials: The following are available online at https://www.mdpi.com/article/10 $.3390 /$ jcm10204634/s1, Figure S1: Prevalence of HF type based on patients' concomitant conditions, Table S1: Patients' baseline characteristics based on the type of HF.

Author Contributions: J.A.G.-O.: Conceptualization, Methodology, Formal Analysis, Writing Original Draft; L.R.-P.: Conceptualization, Methodology, Writing-Reviewing and Editing; M.A.-S.: Conceptualization, Validation, Writing-Reviewing and Editing; V.B.: Conceptualization, Validation, Writing-Reviewing and Editing; J.M.: Conceptualization, Formal Analysis, Data curator, WritingReviewing and Editing; A.P.: Conceptualization, Methodology, Writing-Reviewing and Editing, Supervision. All authors have read and agreed to the published version of the manuscript.

Funding: This research was funded by the Spanish Society of Diabetes (SED) and the Spanish Society of Cardiology (SEC).

Institutional Review Board Statement: The study was conducted in accordance with the Declaration of Helsinki, and it was approved by the Ethics Committee of Toledo Hospital Complex on March 28, 2018 (project identification code 243).

Informed Consent Statement: Informed consent was obtained from all subjects involved in the study.

Conflicts of Interest: Antonio Pérez has served as a consultant for or received research support, lecture fees or travel reimbursement from Sanofi Aventis, Almirall, Novo Nordisk, Eli Lilly, MSD, Boehringer Ingelheim, Esteve, Gilead, Novartis, Amgen, Menarini and Astra Zeneca.

\section{References}

1. Emerging Risk Factors Collaboration; Sarwar, N.; Gao, P.; Seshasai, S.R.; Gobin, R.; Kaptoge, S.; Di Angelantonio, E.; Ingelsson, E.; Lawlor, D.A.; Selvin, E.; et al. Diabetes mellitus, fasting blood glucose concentration, and risk of vascular disease: A collaborative meta-analysis of 102 prospective studies. Lancet 2010, 375, 2215-2222. [PubMed]

2. Shah, A.D.; Langenberg, C.; Rapsomaniki, E.; Denaxas, S.; Rodriguez, M.P.; Gale, C.P.; Deanfield, J.; Smeeth, L.; Timmis, A.; Hemingway, H. Type 2 diabetes and incidence of cardiovascular diseases: A cohort study in 1.9 million people. Lancet Diabetes Endocrinol. 2015, 3, 105-113. [CrossRef]

3. Rawshani, A.; Rawshani, A.; Franzén, S.; Sattar, N.; Eliasson, B.; Svensson, A.M.; Miftaraj, M.; McGuire, D.K.; Rosengren, A.; Gudbjörnsdottir, S.; et al. Risk Factors, Mortality, and Cardiovascular Outcomes in Patients with Type 2 Diabetes. N. Engl. J. Med. 2018, 379, 633-644. [CrossRef]

4. Bell, D.S.H.; Goncalves, E. Heart failure in the patient with diabetes: Epidemiology, aetiology, prognosis, therapy and the effect of glucose-lowering medications. Diabetes Obes. Metab. 2019, 21, 1277-1290. [CrossRef]

5. Jia, G.; Whaley-Connell, A.; Sowers, J.R. Diabetic cardiomyopathy: A hyperglycaemia- and insulin-resistance-induced heart disease. Diabetologia 2018, 61, 21-28. [CrossRef] 
6. Horton, W.B.; Barrett, E.J. Microvascular Dysfunction in Diabetes Mellitus and Cardiometabolic Disease. Endocr. Rev. 2021, 42, 29-55. [CrossRef]

7. Jankowski, J.; Floege, J.; Fliser, D.; Böhm, M.; Marx, N. Cardiovascular Disease in Chronic Kidney Disease: Pathophysiological Insights and Therapeutic Options. Circulation 2021, 143, 1157-1172. [CrossRef]

8. Kidney Disease Improving Global Outcomes (KDIGO) Chronic Kidney Disease Work Group. KDIGO clinical practice guideline for the evaluation and management of chronic kidney disease. Kidney Int. 2013, 3 (Suppl. 3), 1-150.

9. Kalyani, R.R. Glucose-Lowering Drugs to Reduce Cardiovascular Risk in Type 2 Diabetes. N. Engl. J. Med. 2021, 384, 1248-1260. [CrossRef] [PubMed]

10. Buse, J.B.; Wexler, D.J.; Tsapas, A.; Rossing, P.; Mingrone, G.; Mathieu, C.; D'Alessio, D.A.; Davies, M.J. 2019 update to: Management of hyperglycaemia in type 2 diabetes, 2018. A consensus report by the American Diabetes Association (ADA) and the European Association for the Study of Diabetes (EASD). Diabetologia 2019, 63, 221-228. [CrossRef] [PubMed]

11. Packer, M. Heart Failure: The Most Important, Preventable, and Treatable Cardiovascular Complication of Type 2 Diabetes. Diabetes Care 2017, 41, 11-13. [CrossRef] [PubMed]

12. Cosentino, F.; Grant, P.J.; Aboyans, V.; Bailey, C.J.; Ceriello, A.; Delgado, V.; Federici, M.; Filippatos, G.; Grobbee, E.D.; Hansen, T.B.; et al. 2019 ESC Guidelines on diabetes, pre-diabetes, and cardiovascular diseases developed in collaboration with the EASD. Eur. Heart J. 2019, 41, 255-323. [CrossRef] [PubMed]

13. American Diabetes Association Addendum. 10. Cardiovascular Disease and Risk Management: Standards of Medical Care in Diabetes-2020. Diabetes Care 2020, 44, 125-150.

14. American Diabetes Association. 2. Classification and Diagnosis of Diabetes:Standards of Medical Care in Diabetes-2018. Diabetes Care 2018, 41, S13-S27. [CrossRef] [PubMed]

15. Ponikowski, P.; Voors, A.A.; Anker, S.D.; Bueno, H.; Cleland, J.G.; Coats, A.J.; Pieske, B.; Riley, J.P.; Rosano, G.M.C.; Ruilope, L.M.; et al. 2016 ESC Guidelines for the diagnosis and treat-ment of acute and chronic heart failure: The Task Force for the diagnosis and treatment of acute and chronic heart failure of the European Society of Cardiology (ESC). Developed with the special contribution of the Heart Failure Association (HFA) of the ESC. Eur. J. Heart Fail. 2016, 18, 891-975. [PubMed]

16. Conrad, N.; Judge, A.; Tran, J.; Mohseni, H.; Hedgecott, D.; Crespillo, A.P.; Allison, M.; Hemingway, H.; Cleland, J.G.; McMurray, J.J.V.; et al. Temporal trends and patterns in heart failure inci-dence: A population-based study of 4 million individuals. Lancet 2018, 391, 572-580. [CrossRef]

17. Dunlay, S.M.; Givertz, M.M.; Aguilar, D.; Allen, L.A.; Chan, M.; Desai, A.S.; Deswal, A.; Dickson, V.V.; Kosiborod, M.N.; Lekavich, C.L.; et al. American Heart Association Heart Failure and Transplantation Committee of the Council on Clinical Cardiology; Council on Cardiovascular and Stroke Nursing; and the Heart Failure Society of America. Type 2 Diabetes Mellitus and Heart Failure: A Scientific Statement from the American Heart Association and the Heart Failure Society of America: This statement does not represent an update of the 2017 ACC/AHA/HFSA heart failure guideline update. Circulation 2019, 140, e294-e324. [CrossRef]

18. Meta-analysis Global Group in Chronic Heart Failure (MAGGIC). The survival of patients with heart failure with pre-served or reduced left ventricular ejection fraction: An individual patient data meta-analysis. Eur. Heart J. 2012, 33, 1750-1757. [CrossRef]

19. Sacre, J.W.; Magliano, D.J.; Shaw, J.E. Incidence of Hospitalization for Heart Failure Relative to Major Atherosclerotic Events in Type 2 Diabetes: A Meta-analysis of Cardiovascular Outcomes Trials. Diabetes Care 2020, 43, 2614-2623. [CrossRef]

20. Drager, L.F.; McEvoy, R.D.; Barbe, F.; Lorenzi-Filho, G.; Redline, S.; INCOSACT Initiative (International Collaboration of Sleep Apnea Cardiovascular Trialists). Sleep Apnea and Cardiovascular Disease. Lessons from recent trials and need for team science. Circulation 2017, 136, 1840-1850. [CrossRef]

21. Powell-Wiley, T.M.; Poirier, P.; Burke, L.E.; Després, J.P.; Gordon-Larsen, P.; Lavie, C.J.; Lear, S.A.; Ndumele, C.E.; Neeland, I.J.; Sanders, P.; et al. American Heart Association Coun-cil on Lifestyle and Cardiometabolic Health; Council on Cardiovascular and Stroke Nursing; Council on Clinical Cardiol-ogy; Council on Epidemiology and Prevention; and Stroke Council. Obesity and Cardiovascular Disease: A Scientific Statement From the American Heart Association. Circulation 2021, 143, e984-e1010. [PubMed]

22. Kullo, I.J.; Rooke, T.W. CLINICAL PRACTICE. Peripheral Artery Disease. N. Engl. J. Med. 2016, 374, 861-871. [CrossRef] [PubMed]

23. Bonaca, M.P.; Wiviott, S.D.; Zelniker, T.A.; Mosenzon, O.; Bhatt, D.L.; Leiter, L.A.; McGuire, D.K.; Goodrich, E.L.; Furtado, R.H.D.M.; Wilding, J.P.; et al. Dapagliflozin and Cardiac, Kidney, and Limb Outcomes in Patients With and Without Peripheral Artery Disease in DECLARE-TIMI 58. Circulation 2020, 142, 734-747. [CrossRef] [PubMed]

24. Bonaca, M.P.; Nault, P.; Giugliano, R.P.; Keech, A.C.; Pineda, A.L.; Kanevsky, E.; Kuder, J.; Murphy, S.A.; Jukema, J.W.; Lewis, B.S.; et al. Low-Density Lipoprotein Cholesterol Lowering With Evolocumab and Outcomes in Patients With Peripheral Artery Disease: Insights From the FOURIER Trial (Further Cardiovascular Outcomes Research With PCSK9 Inhibition in Subjects With Elevated Risk). Circulation 2018, 137, 338-350. [CrossRef]

25. Verma, S.; Mazer, C.D.; Inzucchi, S.E.; Wanner, C.; Ofstad, A.P.; Johansen, O.E.; Zwiener, I.; George, J.T.; Butler, J.; Zinman, B. Impact of polyvascular disease with and without co-existent kidney dysfunction on cardiovascular outcomes in diabetes: A post hoc analysis of EMPA-REG OUTCOME. Diabetes Obes. Metab. 2021, 23, 1173-1181. [CrossRef] 
26. Neuen, B.L.; Ohkuma, T.; Neal, B.; Matthews, D.R.; de Zeeuw, D.; Mahaffey, K.W.; Fulcher, G.; Blais, J.; Li, M.Q.; Jardine, M.J.; et al. Relative and Absolute Risk Reductions in Cardiovascular and Kidney Outcomes With Canagliflozin Across KDIGO Risk Categories: Findings From the CANVAS Program. Am. J. Kidney Dis. 2021, 77, 23-34.e1. [CrossRef]

27. House, A.A.; Wanner, C.; Sarnak, M.J.; Piña, I.L.; McIntyre, C.W.; Komenda, P.; Kasiske, B.L.; Deswal, A.; Defilippi, C.R.; Cleland, J.G.F.; et al. Heart failure in chronic kidney disease: Conclusions from a Kidney Disease: Improving Global Outcomes (KDIGO) Controversies Conference. Kidney Int. 2019, 95, 1304-1317. [CrossRef]

28. Lee, M.; Kim, K.J.; Chung, T.; Bae, J.; Lee, Y.; Lee, B.; Cha, B.; Yun, M.; Kang, E.S. Nonalcoholic fatty liver disease, diastolic dysfunction, and impaired myocardial glucose uptake in patients with type 2 diabetes. Diabetes Obes. Metab. 2021, 23, $1041-1051$. [CrossRef] [PubMed]

29. Lomonaco, R.; Leiva, E.G.; Bril, F.; Shrestha, S.; Mansour, L.; Budd, J.; Romero, J.P.; Schmidt, S.; Chang, K.-L.; Samraj, G.; et al. Advanced Liver Fibrosis Is Common in Patients With Type 2 Diabetes Followed in the Outpatient Setting: The Need for Systematic Screening. Diabetes Care 2021, 44, 399-406. [CrossRef] 